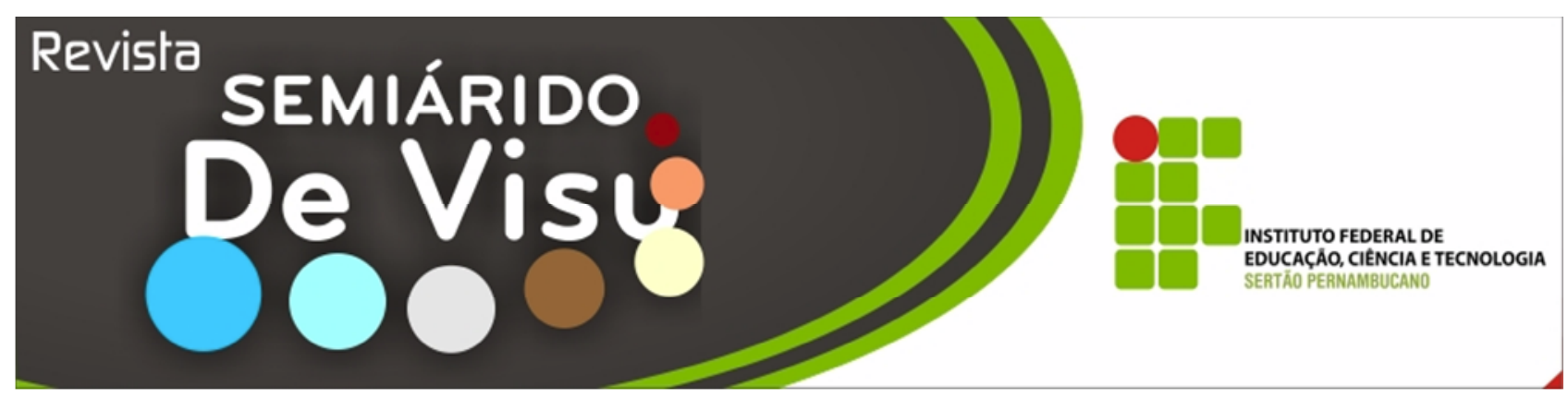

\title{
Caracterização química e sensorial de uvas desidratadas, produzidas no Vale do São Francisco para infusão
}

\author{
Edithe Helena de Brito Santos ${ }^{1}$, Luciana Cavalcanti de Azevêdo ${ }^{1 *}$, Fabiana Pacheco Reis \\ Batista $^{1}$, Laila Pereira Matos ${ }^{1}$, Marcos dos Santos Lima ${ }^{1}$ \\ Instituto Federal de Educação, Ciência e Tecnologia do Sertão Pernambucano - IF SERTÃO-PE, Campus \\ Petrolina, Rodovia BR 407, Km 08, s/n, Bairro Jardim São Paulo, CEP: 56.3000-000, E-mail: \\ lucianac.azevedo@ifsertao-pe.edu.br.
}

\begin{abstract}
RESUMO: A uva é uma fruta típica de região de clima temperado, sendo cultivada para a elaboração de vinhos tradicionais nos países da União Europeia, Estados Unidos, Austrália, Nova Zelândia, África do Sul e América do Sul (Chile e Argentina). No Brasil, além do Rio Grande do Sul, onde as condições climáticas se aproximam dos países tradicionais, a videira foi adaptada para cultivo no Semiárido do Nordeste. A região semiárida brasileira possui um grande potencial para a produção de uvas de alta qualidade durante todo o ano por possuir elevados índices de insolação, favorecendo também a produção de uvas passas de excelentes características organolépticas. O presente trabalho foi desenvolvido com o objetivo de avaliar a probabilidade de serem produzidos materiais desidratados de uvas e seus descartes, a partir das variedades Shirah, Alicante Bouschet, Isabel, Mourvedre, Crimson, Petit Verdot e Red Globe, produzidas no Vale do São Francisco, com a finalidade de serem utilizadas em infusões, como fonte de antocianinas para os consumidores. Com base nos resultados obtidos, verifica-se que os chás foram bem aceitos, inclusive os de uvas das variedades Izabel e Mouvedre foram os chás que apresentaram predominância de aprovação em todos dos atributos sensoriais avaliados. A variedade mais importante como fonte de antocianinas é a Petit Verdot, uma vez que foi classificada neste estudo como uma das duas variedades que apresentou maior teor deste antioxidante, seguida pela Alicante.
\end{abstract}

Palavras-chave: fermentado de fruta, chips de madeira, umburana

\section{Dehydration, characterization and sensorial analysis of grapes dehydrated, produced in the Submédio Valley of the San Francisco, for infusion}

\begin{abstract}
The grape is a typical fruit of region of tempered climate, being cultivated for the elaboration of traditional wines in the countries of the European Union, United States, Australia, New Zelândia, South Africa and South America (Chile and Argentina). In Brazil, beyond the Rio Grande do Sul, where the climatic conditions if approach to the traditional countries, the grapevine was adapted for culture in northeast Semiárido. This Brazilian region presents great potential for the production of grapes of high quality during the year for possessing raised insolation indices, also favoring the production of grapes raisins of excellent sensorial characteristics. The present work was developed with the objective to evaluate the probability to be produced material dehydrated of grapes and its wastes, from the varieties Shirah, Alicante Bouschet, Isabel, Mourvedre, Crimson, Petit Verdot and Red Globe, produced in the Valley of the San Francisco, with the purpose to be used in infusions (tea), as source of antocianinas for the consumers. On the basis of the gotten results, are also verified that the teas had been well accepted, of grapes of the Izabel varieties and Mouvedre had been the teas that had presented predominance of approval in all of the evaluated sensorial attributes. The variety more important as source of antocianinas is the Petit Verdot, a time that was classified in this study as one of the two varieties that greater presented text of this antirust substance, followed for the Alicante.
\end{abstract}

Keywords: fermented of fruit, oak and umburana chips 
Edithe Helena de Brito Santos et al.

\section{Introdução}

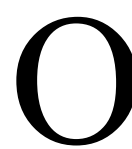

cultivo da videira (Vitis vinifera L.) vem sendo desenvolvido desde a

antiguidade, quando vasos sagrados desenterrados em escavações na Turquia, na antiga cidade de Kannish, mostraram que a viticultura era praticada desde a idade do bronze, há cerca de 3.500 anos a.C (LEÃO; 2000). A viticultura propagou-se por toda a Ásia Menor em direção ao Sul, até a Síria e o Egito. Na Grécia, alcançou extraordinário progresso, impregnando sua história, tradições e religiões. Segundo Leão (2000), no Brasil, o cultivo da videira teve início por volta de 1532, proveniente da ilha de Madeira, Açores e outras partes do Reino Português, trazido pelos colonizadores portugueses. Foi a partir da segunda guerra que a viticultura brasileira passou a ter importância comercial. Hoje, espalha-se pelas terras brasileiras, em regiões cujas características de clima e solo se diferem (MONTEIRO, 2007; SOUZA, 2008).

A viticultura se tornou uma atividade de grande importância no Brasil, especialmente para a sustentabilidade da pequena propriedade, que nos últimos anos tem se tornado essencial na geração de emprego e em grandes empreendimentos para produção de uvas de mesa e uvas para processamento. De acordo com Mello (2007), a produção nacional em 2008 foi de 1.399, 262 toneladas, 3,27\% superior ao ano de 2007, e atingindo 1,35 milhões de toneladas, numa área cultivada de 89,9 mil hectares (DANNE et al., 2009).

De acordo com o IBGE (2007), os maiores pólos produtores de uva no Brasil obedecem à seguinte ordem: em primeiro lugar Rio Grande do Sul com uma produção de 623.878 t, seguido por São Paulo com 195.357 t; Pernambuco com 155.781 t; Bahia com uma produção de 117.111 t e Paraná com uma produção de $95.357 \mathrm{t}$. A viticultura na região semiárida, em particular no Submédio São Francisco, se destaca no cenário nacional, não apenas pela expansão da área cultivada e do volume de produção mas, principalmente, pelos altos rendimentos alcançados e na qualidade da uva produzida (SOUZA, 2008). A produção de uva no Vale do Submédio São Francisco concentra-se, nos municípios de Petrolina e Santa Maria da Boa Vista, em Pernambuco, com $54 \%$ da área cultivada e Juazeiro, Curaçá, Sento Sé e Casa Nova, na Bahia, que detém os $46 \%$ restantes de área (SILVA \& CORREIA, 2000).

Convém ressaltar a especificidade da viticultura na região semiárida do Nordeste brasileiro (Submédio São Francisco) em virtude da adaptação e do comportamento diferenciado nessas condições climáticas. Os processos fisiológicos das plantas são acelerados, a propagação é muito rápida e em cerca de um ano e meio, após o plantio, inicia-se a primeira safra. Considerando que o ciclo de produção oscila em torno de 120 dias, pode-se obter até duas safras por ano, mediante o manejo da irrigação e a realização de podas programadas. Isto possibilita a produção durante todo o ano e uma produtividade elevada da ordem de 40 t/ha/ano, bem acima das obtidas nas demais regiões produtoras brasileiras (ARAÚJO, 2003).

Além de suas características sensoriais atrativas, a uva tem despertado o interesse pela riqueza em componentes antioxidantes como as antocianinas. Estas são incluídas no grupo de pigmentos de ocorrência natural, entre os flavonóides, e são responsáveis pela enorme diversidade de cores das flores e dos frutos. A palavra antociana deriva do grego anthos (flor) e kyanos (azul). São pigmentos que não se encontram em animais, plantas marinhas ou microrganismos, apenas em vegetais. Além do papel na coloração, elas também têm outras funções nas plantas nomeadamente na proteção das radiações UV, na defesa contra patogênicos e na polinização (GOLLOP et al. 2001; MARTENS et al. 2003).

As antocianinas (Figura 1), em particular, são consideradas substâncias bioativas que ocorrem em pequenas quantidades nos alimentos e possuem potencial antioxidante, atuando como redutores de oxigênio singleto, na inibição das reações de oxidação lipídica e na quelação de metais. Além disso, apresentam uma ampla gama de propriedades farmacológicas, como antialergênicas, anti-arteriogênicas, 
Edithe Helena de Brito Santos et al.

antiinflamatórias, antitrombóticas cardioprotetores e $\mathrm{e}$

antimicrobianas, também efeitos vasodilatadores (PUUPPONEN-PIMIÄ et al., 2001). Estudos clínicos e epidemiológicos têm mostrado evidências de que antioxidantes fenólicos de cereais, frutas e vegetais são os principais fatores que contribuem para a baixa e significativa redução da incidência de doenças crônicas e degenerativas encontradas em populações cujas dietas são altas na ingestão desses alimentos (SHAHIDI, 1996).<smiles>[R2]Oc1cc(O)cc2[o+]c(-c3cc([R])c(O)c([R])c3)c([R20])cc12</smiles>

Figura 1. Estrutura química básica das antocianinas.

As antocianinas estão presentes principalmente nas primeiras camadas de células da casca da uva, com exceção de poucas variedades cuja polpa também é pigmentada. Esses pigmentos possuem diferentes cores, em tons de azul, vermelho, rosa, violeta e púrpura, responsáveis pela cor do vinho tinto recém elaborado, e de fácil extração por água (RANKINE, 1989). A malvidina, o principal tipo de pigmento da uva, representa, no mínimo, $50 \%$ da concentração total das antocianinas (CABRITA et al., 2003; ROGGERO et al., 1986).

Esses componentes podem ser acentuados com a eliminação da água livre presente na uva, após a secagem do fruto no qual estava presente. A secagem de frutos para o consumo surgiu na Europa, durante o Império Romano. Os frutos são submetidos a processos de secagem natural, exposição ao sol ou artificial, câmaras de ar, vapor ou estufas e mesmo assim não perdem suas propriedades nutricionais (SBRT, 2005).

As vantagens do processo de secagem são inúmeras, as quais pode-se destacar a manutenção mais eficiente das características originais do produto, redução de seu peso e um preço relativamente compensatório, devido à perda de água. A umidade é um fator fundamental ao crescimento e desenvolvimento dos microrganismos. Dessa forma, ao diminuir significativamente o seu conteúdo, estará criando condições desfavoráveis para 0 desempenho das atividades metabólicas dos microrganismos (GAVA, 2002).

Segundo Matos (2007) as frutas desidratadas são excelentes fontes de vitaminas e minerais, possuem alto teor calórico e, incorporadas a uma alimentação equilibrada, acarretam enormes benefícios à saúde, como também agregam valor ao produto, mas a qualidade final desses produtos desidratados dependerá da matéria prima utilizada,. Para garantir qualidade e atender aos padrões exigidos nas normas de qualidade e higiene estabelecidas pela legislação, as frutas desidratadas, secas ou dessecadas, devem ser obtidas com frutas maduras, inteiras ou em pedaços e envolver tecnologias apropriadas, garantindo um produto saudável, sem alterações no sabor, na cor e na textura (SANTOS et al., 2010).

Os processos usuais de desidratação da uva, por meio de exposição ao sol, são inviáveis para a maioria das vinícolas brasileiras, devido à alta incidência de chuvas no período da safra. Nas condições climáticas do vale do São Francisco, este problema não chega a ser impedimento para o uso da secagem solar, uma vez que a região possui uma média de $2.800 \mathrm{~h}$ de insolação por ano e pluviosidade baixa e irregular, com 
Edithe Helena de Brito Santos et al.

precipitação aproximada de $750 \mathrm{~mm} / \mathrm{ano}$ (EMBRAPA, 2011).

Diante da facilidade apresentada pela região em produzir uvas e, ao mesmo tempo, de secá-las de forma natural e em grandes proporções, o presente trabalho foi desenvolvido com o objetivo de avaliar a probabilidade de serem produzidos materiais desidratados de uvas e seus descartes, a partir das variedades Shirah, Alicante Bouschet, Isabel, Mourvedre, Crimson, Petit Verdot e Red Globe, produzidas no vale do submédio São Francisco, com a finalidade de serem utilizadas em infusões (chás), como fonte de antocianinas para os consumidores.

\section{Material e métodos}

\section{Preparo das amostras}

As atividades foram desenvolvidas no Laboratório Experimental de Alimentos (LEA) e as analises físico-químicas foram executadas no Laboratório de Físico-Química, ambos do Instituto Federal de Educação, Ciência e Tecnologia de Sertão Pernambucano (IF
SERTÃO-PE) Campus Petrolina - situado a rodovia BR 407, km 8, Jardim São Paulo, Petrolina -PE.

As uvas das variedades Isabel, Syrah, Mourvedre, Petit Verdot, Red Globe e Crimson, utilizadas na execução do experimento foram provenientes das vinícolas do vale do Submédio São Francisco, no período de maio de 2010 a fevereiro de 2011. As frutas foram transportadas para o laboratório experimental onde foram selecionadas de acordo com seus atributos de qualidade: o estádio de maturação e similaridade na cor das películas.

Os frutos selecionados foram lavados, sanificados, pesados, cortados manualmente ao meio, retiradas as sementes e pesados novamente, em seguida foram dispostos em bandejas perfuradas e encaminhados para o secador de fluxo continuo, com temperatura de $70^{\circ} \mathrm{C}$ (Figura 2). Durante a secagem, as bandejas foram retiradas do secador com um tempo estabelecido (a cada 1hora), avaliando o comportamento dos frutos, em relação ao peso da amostra (g) e tempo (h), para a obtenção da cinética de secagem.

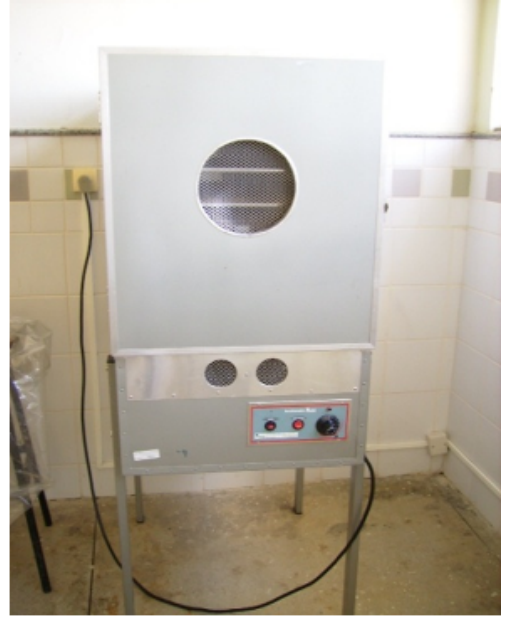

Figura 2. Secador elétrico com circulação de ar forçado.

Após secagem, realizou-se a trituração das amostras desidratadas para obtenção do pó, utilizando multiprocessador doméstico. $3 \mathrm{~g}$ do pó produzido foram depositados em saquinho confeccionado com material poroso (papel de filtro) (Figura 10), para simulação da embalagem tipo sachê, em seguida foram submetidos à esterilização (UV) $15 \mathrm{~min}$ e armazenadas (Figura 3). 
Edithe Helena de Brito Santos et al.

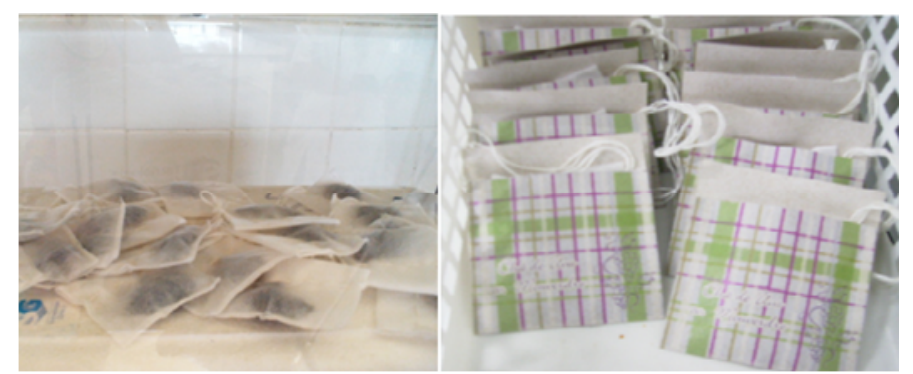

Figura 3. Pó de uvas acondicionadas em saquinhos e saquinhos armazenados.

\section{Análises Físico-Químicas e sensoriais}

As amostras de uvas in natura e desidratadas foram submetidas às analises físico-químicas em triplicatas: atividade de água (aw), sólidos solúveis, acidez titulável, determinação de $\mathrm{pH}$, umidade e antocianinas totais, realizadas no Laboratório de FísicoQuímica do IF SERTÃO-PE de acordo com as metodologias descritas por Ribereau-Gayon et al. (2003) e IAL (2005).

A determinação da atividade de água foi realizada diretamente, com a utilização de higrômetro (Aqualab Decagon Devices, modelo Série 3TE).

As infusões obtidas das amostras desidratadas foram submetidas a testes sensoriais comparativos, para que os provadores pudessem avaliar se as características sensoriais dos frutos in natura estavam mantidas nos frutos desidratados $\mathrm{e}$ testes sensoriais qualitativos, para escolha do produto que apresentasse melhores características sensoriais.

O teste de aceitação dos chás foi realizado por um grupo de 20 (vinte) degustadores não treinados de ambos os sexos, formado por alunos do curso de Tecnologia em Viticultura e Enologia e servidores do IF SERTÃO - PE, utilizando um formulário com escala hedônica estruturada, contendo nota mínima (desgostei extremamente), e nota máxima (gostei extremamente) para os atributos: sabor, aroma, intenção de compra e novidade, conforme metodologia descrita por Minim (2006) com algumas modificações. A avaliação foi realizada no Laboratório Experimental de Alimentos (LEA), IF SERTÃO-PE Campus Petrolina.

Para o teste sensorial utilizaram-se xícaras de vidro, onde foram distribuídos os saquinhos contendo os sachês e foram servidos, de maneira ordenada, de acordo com as variedades de uvas. Os sachês foram imersos em $100 \mathrm{~mL}$ de água destilada fervente e deixados por 3 minutos, conforme metodologia adaptada de Hertog et al. (1993). Em seguida, os sachês eram removidos da infusão. Para melhor neutralização dos sabores entre cada amostra, utilizou-se biscoito a base de sal e água mineral natural.

\section{Resultados e discussão}

Secagem das uvas

As representações gráficas do comportamento dos frutos da uva Shiraz, Mourvedre, Isabel, Crimson, Petit Verdot, Red Glob e Alicante Bouschet, durante a secagem estão representas na Figura 4, mostrando os valores decrescentes de peso, para os tempos de secagem estudados. 
Edithe Helena de Brito Santos et al.

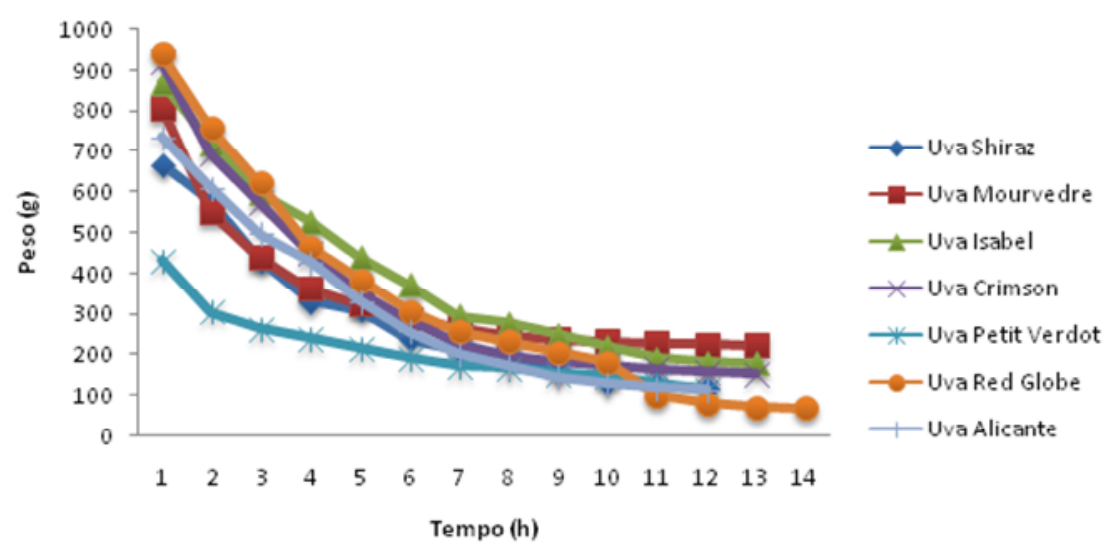

Figura 4. Curvas de secagem das uvas (Temperatura $70^{\circ} \mathrm{C}$ ).

As secagens tiveram inicio nas primeiras horas em que as bagas foram dispostas no interior do secador, com nível de temperatura de $70^{\circ} \mathrm{C}$. Nesse período ocorreu uma elevação gradual da temperatura das bagas e da pressão de vapor de água. Essas elevações tiveram prosseguimento até o ponto em que a transferência de calor foi equivalente à transferência de massa (água). Depois, foi possível observar que a taxa de redução do teor de umidade alcançou um valor constante. A água evaporada foi aágua livre, quando a transferência de massa e de calor foi equivalente e, portanto, a velocidade de secagem era constante (EMBRAPA, 1989; Gava, 2002). E assim permaneceu até que não se tinha mais água na superfície do produto suficiente para acompanhar a evaporação, quando a taxa de secagem era constante. Após sete horas percebeu-se que a taxa de secagem começava a decrescer devido à redução da quantidade de água presente na superfície do produto. Assim, após 10 (dez) horas tinha-se uma redução da taxa do teor de umidade o que indicava que o ponto de umidade de equilíbrio em relação ao ar de secagem começava a se aproximar, indicando o fim do processo de secagem.
Comparando-se o tempo de secagem gasto pelas variedades de uvas analisadas, observa-se que as cultivares Petit Verdot e Shiraz necessitaram de um menor tempo de secagem para obter taxa constante, e por outro lado a cultivar Red Globe necessitou de um maior tempo de secagem. Esses resultados estão relacionados às diferentes dimensões e condições de textura das amostras entre si, o que facilitou a remoção da umidade presente nas uvas de algumas variedades e dificultou de outras.

Análises físico-quimicas das uvas in natura e desidratadas

Conforme dados descritos nas Tabelas 1 e 2, foram analisados os principais parâmetros físico-químicos nas uvas Syrah, Mourvedre, Isabel, Crinsom, Petit Verdot, Red Globe e Alicante in natura e desidratada, no vale do Submédio São Francisco. 
Edithe Helena de Brito Santos et al.

Tabela 1. Parâmetros analiticos das uvas in natura

\begin{tabular}{l|c|c|c|c|c|c}
\hline TRATAMENTOS & \multicolumn{7}{|c}{ Análises } \\
\cline { 2 - 7 } & $\mathrm{pH}$ & $\begin{array}{l}\text { Sólidos so hiveis } \\
\text { ("Brix) }\end{array}$ & Acidez (\%) & aw & Umidade (\%) & Antocianinas \\
\cline { 2 - 7 } T1- Shiraz & $3,80 \mathrm{a}$ & $14,7 \mathrm{~d}$ & $3,9 \mathrm{~b}$ & $0,99 \mathrm{a}$ & $80,0 \mathrm{a}$ & $101 \mathrm{~b}$ \\
T2- Mbuvedre & $3,04 \mathrm{f}$ & $14,3 \mathrm{~b}$ & $4,9 \mathrm{a}$ & $0,99 \mathrm{a}$ & $86,7 \mathrm{a}$ & $\mathrm{ND}$ \\
T3- Isabe1 & $3,73 \mathrm{~b}$ & $15,0 \mathrm{~b}$ & $4,4 \mathrm{a}$ & $0,99 \mathrm{a}$ & $79,9 \mathrm{a}$ & $54 \mathrm{c}$ \\
T4- Crimson & $3,62 \mathrm{c}$ & $11,8 \mathrm{c}$ & $3,7 \mathrm{~b}$ & $0,98 \mathrm{a}$ & $80,4 \mathrm{a}$ & $15 \mathrm{e}$ \\
T5- Petit Verdot & $3,29 \mathrm{e}$ & $15,4 \mathrm{~d}$ & $4,7 \mathrm{a}$ & $0,99 \mathrm{a}$ & $82,1 \mathrm{a}$ & $535 \mathrm{a}$ \\
T6- Red Globe & $3,45 \mathrm{~d}$ & $11,3 \mathrm{c}$ & $4,0 \mathrm{~b}$ & $0,96 \mathrm{~b}$ & $86,0 \mathrm{a}$ & $\mathrm{ND}$ \\
T7- Alicante & $3,83 \mathrm{a}$ & $17,0 \mathrm{a}$ & $4,1 \mathrm{~b}$ & $0,98 \mathrm{a}$ & $81,5 \mathrm{a}$ & $124 \mathrm{~d}$ \\
\hline \multicolumn{1}{c}{ CV } & $0,9 \%$ & $9,6 \%$ & $7,1 \%$ & $1,1 \%$ & $10,9 \%$ & $13,5 \%$ \\
\hline
\end{tabular}

Médias seguidas de letras iguais, na coluna, não diferem entre si pelo teste de Scott-Knott a $5 \%$ de probabilidade.

Tabela 2 . Parâmetros analiticos das uvas desidratadas

\begin{tabular}{l|c|c|c|c|c}
\hline \multirow{2}{*}{ TRATAMENTOS } & \multicolumn{5}{|c}{ Análises } \\
\cline { 2 - 6 } & $\mathrm{pH}$ & Umidade (\%) & Acidez (\%) & $\mathrm{aw}$ & Antocianinas \\
\hline T1- Shiraz & $3,86 \mathrm{~b}$ & $10,7 \mathrm{~d}$ & $6,0 \mathrm{~b}$ & $0,47 \mathrm{c}$ & $103 \mathrm{c}$ \\
T2- Mbuvedre & $3,76 \mathrm{~b}$ & $17,8 \mathrm{c}$ & $2,4 \mathrm{~d}$ & $0,48 \mathrm{c}$ & $71 \mathrm{~d}$ \\
T3- Isabel & $3,75 \mathrm{~b}$ & $15,4 \mathrm{~b}$ & $2,9 \mathrm{~d}$ & $0,43 \mathrm{~d}$ & $40 \mathrm{e}$ \\
T4- Crimson & $3,58 \mathrm{c}$ & $15,0 \mathrm{~b}$ & $6,4 \mathrm{~b}$ & $0,68 \mathrm{a}$ & $\mathrm{ND}$ \\
T5- Petit Verdot & $4,12 \mathrm{a}$ & $18,0 \mathrm{c}$ & $3,7 \mathrm{c}$ & $0,46 \mathrm{c}$ & $358 \mathrm{~b}$ \\
T6- Red Globe & $3,52 \mathrm{c}$ & $21,0 \mathrm{~d}$ & $10,7 \mathrm{a}$ & $0,54 \mathrm{~b}$ & $36 \mathrm{e}$ \\
T7- Alicante & $3,74 \mathrm{~b}$ & $19,1 \mathrm{c}$ & $10,1 \mathrm{a}$ & $0,49 \mathrm{c}$ & $216 \mathrm{a}$ \\
\hline \multicolumn{1}{c|}{ CV } & $1,7 \%$ & $6,2 \%$ & $8,1 \%$ & $2,2 \%$ & $5,44 \%$ \\
\hline
\end{tabular}

*Médias seguidas de letras iguais, na coluna, não diferem entre si pelo teste de Scott-Knott a 5\% de probabilidade.

O pH nos alimentos é uma variável que depende de vários fatores, dentre os quais, o estado de conservação da matéria-prima utilizada, bem como de suas condições microbiológicas, e interfere de maneira significativa no desenvolvimento de microrganismos. Os padrões de qualidade e identidade (PIQ's), atualmente vigente na legislação brasileira, determinam que o valor de
$\mathrm{pH}$ para polpas de frutas deve variar entre 3,30 e 4,50 (BRASIL, 2000). Conforme verificado nas Tabelas 1 e 2, as variedades de uvas apresentaram diferenças significativas para os valores de $\mathrm{pH}$, permanecendo numa faixa de 3,04 e 3,83 e os das uvas desidratadas variou de 3,52 a 4,12 encontrando-se dentro dos padrões, para todas as amostras. Observa-se que, em cinco, das sete variedades de uvas 
Edithe Helena de Brito Santos et al.

estudadas, o processo de secagem promoveu um discreto aumento nos valores de $\mathrm{pH}$, estando este fenômeno relacionado à degradação de ácidos orgânicos da uva.

Diversos autores afirmam que durante o amadurecimento de uvas, a concentração de açúcares, aminoácidos, compostos fenólicos e potássio tende a aumentar, enquanto ácidos orgânicos, particularmente o ácido málico, apresentam diminuição (COOMBE, 1987; OLLAT et al., 2002; ADAMS, 2006).

$\mathrm{Na}$ caracterização química, a acidez e os sólidos solúveis são as variáveis que mais interessam à indústria de processamento de frutos. $\mathrm{O}$ teor de sólidos solúveis totais, expresso em ${ }^{\circ}$ Brix é uma medida indireta do teor de açúcares do fruto e a relação sólidos solúveis totais e acidez total titulável têm sido associados ao estádio de maturidade fisiológica dos frutos (SEYMOUR et al., 1993). O teor de sólidos solúveis totais pode ser considerado baixo, na maioria das cultivares analisadas, permanecendo numa faixa de $11,3^{\circ}$ a $17,0^{\circ}$ Brix (Tabela 1), ficando abaixo do recomendado pelas normas internacionais de comercialização, que é de $17^{\circ}$ Brix para uvas de mesa (BARROS et al., 1995); sendo adotada no vale do São Francisco, para as variedades sem sementes, valores mínimos de $15^{\circ}$ Brix.

A acidez encontrada nas uvas in natura permaneceu numa faixa de 3,9 a 4,9 g de ácido tartárico/100 mL de suco, sendo superior ao encontrado por Souza-Leão \& Pereira (2001) em outras variedades de uva $(0,91 \mathrm{~g}$ de ácido tartárico/100 $\mathrm{mL}$ de suco). Esse valor de acidez titulável possivelmente ocorre por causa das altas temperaturas na região $\left(30^{\circ} \mathrm{C}\right.$ a $\left.37{ }^{\circ} \mathrm{C}\right)$, que coincidem com a época de maturação das bagas. As uvas desidratadas obtiveram faixas de acidez entre 2,4 a 10,7 g de ácido tartárico/100 mL de suco e isso significa que todas apresentaram alta acidez. Carvalho \& Chitarra (1984) comentam que valores acima de 1,5\% são considerados elevados para frutas. Para algumas variedades de uva como Shiraz, Crimsom, Red Globe e Alicante, a acidez titulável foi aumentada nos frutos desidratados, como ocorreu com a maioria dos demais parâmetros físico-químicos. Observa-se, no entanto, que para as variedades Mouvedre,
Isabel e Petit verdot este comportamento não se repete, havendo diminuição nos teores de acidez associada à degradação de ácidos orgânicos, conforme já discutido anteriormente.

O tempo de vida do produto, bem como sua textura, consistência e viscosidade estão diretamente relacionados ao teor de água presente. Essa quantidade de água é chamada de atividade de água $\left(\mathrm{a}_{\mathrm{W}}\right)$, e é medida para determinar a susceptibilidade do produto à degradação (OLIVEIRA, 2008). Nas uvas in natura, a atividade de água apresentou valores iguais ou superiores a 0,96. Com a desidratação, caiu para um faixa de 0,43 a 0,68. Os principais fatores responsáveis pelo crescimento de microrganismos em frutas estão relacionados com atividades de água superiores a 0,82 (NORTHOLT et. al., 1978). Portanto, a atividade de água encontrada nas amostras desidratadas revela a possibilidade de se obter um maior tempo de uso para as frutas.

$\mathrm{O}$ teor de umidade das uvas in natura encontrou-se dentro de uma faixa de $79,9 \%$ a $86,7 \%$, reduzindo-se significamente para uma faixa de $10,7 \%$ a $21,0 \%$ com a desidratação. Tais valores estão dentro da faixa esperada para alimentos de alta umidade (CHIRIFE \& FAVETO, 1992).

Os valores obtidos de antocianinas para as uvas in natura variaram entre 15 e 535 e nas desidratadas entre 36 e 216 para as cultivares analisadas. De acordo com a literatura, o conteúdo de antocianinas encontrado em uvas tintas varia de 30 a $750 \mathrm{mg} 100 \mathrm{~g}^{-1}$ na fruta madura. Assim, as amostras analisadas se encontram dentro deste padrão estabelecido. Em pesquisa feita por Soares et al. (2008), com as cascas de uvas das cultivares 'Niágara' e 'Isabel', o conteúdo de antocianinas totais variava entre 7,02 e $82,15 \mathrm{mg} 100 \mathrm{~g}^{-1}$ de peso fresco para as cultivares, valores inferiores às concentrações encontradas neste trabalho.

Diante dos resultados apresentados na caracterização físico-química das uvas, pode-se observar variações no comportamento dos valores médios das variáveis de $\mathrm{pH}$, acidez titulável e antocianinas para as variedades de uva in natura, comparando-se com à desidratada.. Para as variáveis umidade e atividade de água, observou-se uma diminuição 
Edithe Helena de Brito Santos et al.

nas suas concentrações, relacionado com $\mathrm{o}$ processo da desidratação aplicado na matériaprima.

Análise sensorial do chá de uva

Os resultados dos atributos sensoriais avaliados nos chás de uvas estão apresentados nas Tabelas 3 e na Figura 5, as quais expressam os valores médios das notas atribuídas pelos provadores. De acordo com resultados, os atributos analisados para os chás foram bem pontuados com notas médias superiores a $6,0 \mathrm{e}$ isto evidencia uma boa aceitação desta bebida.

Tabela 3. Nota média atribuida pelos provadores dos chás de uvas.

\begin{tabular}{l|c|c|c}
\hline \multicolumn{3}{|c}{ TRATAMENTOS } & \multicolumn{3}{|c}{ Variáreis analisad as } \\
\hline & Aroma & Cor & Sabor \\
T1- Shiraz & $5,4 \mathrm{a}$ & $7,7 \mathrm{a}$ & $6,6 \mathrm{a}$ \\
T2- Mouvedre & $6,5 \mathrm{a}$ & $8,1 \mathrm{a}$ & $7,4 \mathrm{a}$ \\
T3- Isabel & $5,8 \mathrm{a}$ & $7,5 \mathrm{a}$ & $7,4 \mathrm{a}$ \\
T4- Crimson & $5,7 \mathrm{a}$ & $7,1 \mathrm{a}$ & $6,7 \mathrm{~b}$ \\
T5- Petit Verdot & $6,2 \mathrm{a}$ & $7,7 \mathrm{a}$ & $6,6 \mathrm{~b}$ \\
T6- Red Globe & $6,4 \mathrm{a}$ & $5,3 \mathrm{~b}$ & $6,3 \mathrm{~b}$ \\
T7- Alicante & $6,1 \mathrm{a}$ & $4,9 \mathrm{~b}$ & $6,0 \mathrm{~b}$ \\
\hline \multicolumn{1}{c|}{ CV\% } & 25 & 23,2 & 25,3 \\
\hline
\end{tabular}

\section{*Médias seguidas de letras iguais, na coluna, não diferem entre si pelo teste de Scott-Knott a 5\% de probabilidade.}

O processamento de chá de uva possibilita uma maior valorização do fruto da videira. Visto que, de acordo com Reto et al. (2008) o chá tornou-se uma das bebidas mais populares no mundo, devido não só ao seu sabor e aroma agradáveis, mas também aos efeitos benéficos para a saúde. É uma bebida de composição química muito variada e embora os efeitos benéficos estejam predominantemente associados ao seu teor em catequinas, o chá também é rico em vários minerais e oligoelementos essenciais para a saúde, como por exemplo, os fluoretos.
Pode-se observar que os chás das cv. Isabel e Mouvedre foram bem pontuados no atributo "sabor", assim como no atributo "cor", juntamente com as variedades Shiraz e Petit Verdot.. A intensidade da cor do chá de uva é um dos principais atributos que afeta $o$ consumo, estando diretamente relacionado com a quantidade e a qualidade dos pigmentos que nele se encontram. Fatores como variedade, maturação e tipo de processamento têm papel fundamental na cor final apresentada pelo produto após o processamento. Isto evidentemente irá influenciar também na decisão de compra, pelo consumidor. 
Edithe Helena de Brito Santos et al.

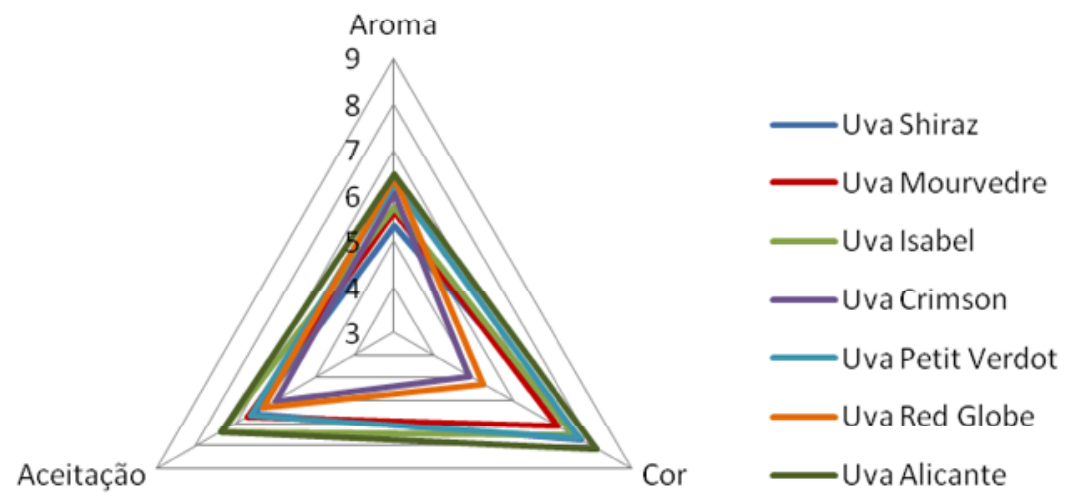

Figura 5. Notas médias atribuídas aos parâmteros sensoriais dos chás de diferentes variedades de uva

O aroma, por vezes, é entendido como o somatório de vários aspectos que sensibilizam o avaliador não treinado na determinação das diferenças e similaridades entre os chás das variedades de uvas, identificando a preferência do consumidor pelos produtos e melhorias no processamento. No entanto, nos chás das variedades estudadas, não houveram notas com diferenças significativas para este atributo.

Todos os chás obtiveram $100 \%$ de aceitação para o caráter inovador. Dessa forma, evidencia a importância de desidratar a uva, com boas características sensoriais e nutricionais, para ser aproveitada como infusão (chá), além de contribuir para minimizar perdas no processamento, pode proporcionar inúmeros benefícios à saúde humana (KHAN \& MUKHTAR, 2007).

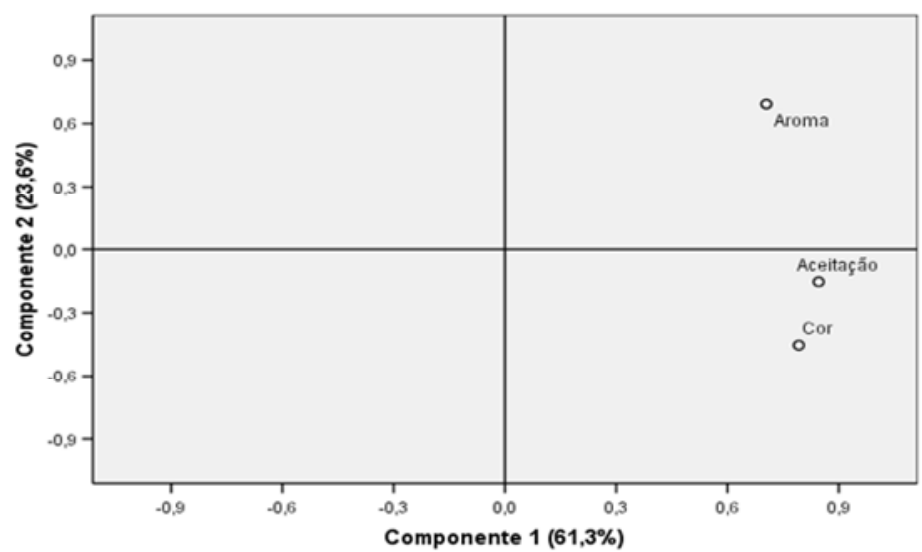

Figura 6. Figura bidimensional da análise dos Componentes Principais dos chás das diferentes variedades de uvas. (Figura 6), na qual as configurações dos atributos sensoriais dos chás de uvas e a distribuição bidimensional dos mesmos foram representadas, cada eixo explica uma porcentagem da variação total que existe entre as amostras.

Verificam-se que $61,3 \%$ da variação ocorrida entre as amostras foram explicadas pelo primeiro eixo (Componente Principal 1).

Os Componentes Principais 1 e 2 explicaram juntos $84,9 \%$ da variação ocorrida entre as amostras de chá de uvas. Isto demonstra que os descritores empregados discriminam satisfatoriamente as amostras analisadas. 
Edithe Helena de Brito Santos et al.

De acordo com MUÑOZ et al. (1992), em uma figura que represente a ACP, vetores com medidas mais distantes de zero, referem-se às variações com maior influência sobre o valor do Componente Principal, enquanto, vetores mais próximos de zero, indicam que correspondem a uma variável com pequena influência sobre o Componente Principal. Portanto, é possível verificar que todos os atributos gerados para as amostras de chás de uvas, correspondem às variações com grande influência.

Por observação da Figura 6 é possível afirmar que o atributo cor exerceu maior influência sobre a aceitação dos chás de uvas, evidenciando a importância do conteúdo antociônico na aceitação desta bebida.

\section{Conclusões}

A uva, consumida e/ou comercializada na forma in-natura, apresenta elevado desperdício, e a secagem das frutas é uma das alternativas para minimização dessa perda. $\mathrm{O}$ beneficiamento em forma de chá é também uma opção para valorização dos produtos, uma vez que os derivados beneficiados alcançam melhores preços no mercado, além de aumentar a vida útil da fruta.

Com base nos resultados obtidos, verifica-se que os chás de uvas das variedades Mouvedre e Izabel apresentaram predominância de aprovação em todos os atributos sensoriais avaliados, bem como grande aceitação dos produtos, caso essem estivessem à venda. É possível perceber que o atributo "cor" possui grande influência sobre a aceitação dos chás de uvas estudados, sendo indicadas as variedades tintas para elaboração deste tipo de produto.

Dessa forma, pelas suas propriedades sensoriais, o chá de uva representa uma alternativa não só de aproveitamento do fruto, bem como de fonte de nutrientes essenciais ao corpo, como as antocianinas. As principais fontes deste nutrientes, entre as variedades estudadas, foram a Petit Verdot e Alicante.

$O$ fato de o chá de uva ter sido bem aceito sinaliza para a possibilidade de projeção mercadológica de um produto em escala comercial com consumidores em potencial. Os resultados do presente estudo revelam a necessidade de combinação entre variedades de uvas que possibilitem o equilíbrio entre as características sensoriais das uvas e o aporte de antocianinas, para obtenção de um produto final com boa qualidade sensorial e nutricional.

\section{Agradecimentos}

Os autores agradecem ao IF SERTÃO$\mathrm{PE}$, especialmente à Pró-Reitoria de Pesquisa, Inovação e Pós-Graduação, pelo apoio concedido à pesquisa e pela Bolsa de Iniciação Científica concedida à primeira autora. Os nossos agradecimentos a todos os profissionais que contribuíram para a construção deste trabalho.

\section{Referências}

ADAMS, D. O. Phenolics and ripening in grape berries. American Journal of Enology and Viticulture, 57, 2006, 249-256.

AOAC. Official methods of analysis of the Association Analytical Chemists. 18.ed. Gaithersburg, Maryland, 2005.

ARAUJO, J. L. P.; CORREIA, R. C.; GUIMARÃES, J.; ARAUJO, E. P. Analise do custo de produção e Comercialização da manga produzida e exportada na região do Submédio São Francisco. In: CONGRESSO BRASILEIRO DE ECONOMIA E SOCIOLOGIA RURAL, 41., 2003, Juiz de Fora, Anais... Juiz de Fora; SOBER; Embrapa Gado de Leite; CES/JF; UFLA;

UFSJ; UFV, 2003. 1 CD - ROM.

BARROS, J.C. da S.M. de; FERRI, C.P.; OKAWA, H. Qualidade da uva fina de mesa comercializada na Ceasa de Campinas, 1993 1994. Informações Econômicas, São Paulo, v. 25, n.7, p. $53-61,1995$. 
Edithe Helena de Brito Santos et al.

BRASIL, Leis, Decretos, etc. Instrução normativa $\mathrm{N}^{\mathbf{1}} 1$ de 7 de janeiro de 2000 . Seção 1., p.54-58. Regulamento técnico geral para a fixação dos padrões de identidade e qualidade para polpa de fruta.

CABRITA, J. M.; SILVA, J. R.; LAUREANO, O. Os compostos polifenólicos das uvas e dos vinhos. In: I Seminário Internacional de Vitivinicultura. Local: Ensenada, México. 24 e 25 de Setembro de 2003.

CARVAlHO, V. D.; CHITARRA, M. I. F. Aspectos quantitativos da uva. Informe Agropecuário, Belo Horizonte, v. 10, n. 117, p. 75-79, 1984.

CHIRIFE, J.; FAVETO, G.J. Some physicochemical basis of food preservation by combined methods. Food Research International, Kidlington, v.25, n.5, p.389396, 1992.

COOMBE, B. Influence of temperature on composition and quality of grapes. In: Proceedings of the International Symposium on Grapevine Canopy and Vigor Management, XXII IHC pp. 23-35. Davis, USA: ISHS Acta Horticulturae 206, 1987.

DANNE, M. A.; CITADIN, I.; SASSO, S. A. Z.; ZARTH' N. A.; MAZARO, S. M. Fontes de cálcio aplicadas no solo e sua relação com a qualidade da uva 'Vênus'. Revista Brasileira de

vol.31, n.3, Jaboticabal Sept. 2009.

EIDAM, T.; SANCHES, M. G. Estudo do perfil do consumidor de minimamente processado do municipio de ponta grossa. UTFPR, 2009.

EMBRAPA. Produção de passas através da desidratação artificial na região semi-árida brasileira. CT/38, CPATSA, julho 1989, p.2. Disponível em:

http://www.infoteca.cnptia.embrapa.br/

bitstream/doc/133669/1/COT38.pdf $>$. Acesso em: 11 de julho de 2011.

EMBRAPA. Seminário Internacional debate efeitos das mudanças do clima sobre a vitivinicultura regional e mundial. Disponível em: $<$ http://www.cpatsa.embrapa.br:8080/ noticias/noticia151.php $>$. Acesso em: $25 \mathrm{dez}$. 2010.

GAVA, A. J. Princípios de tecnologia de alimentos. São Paulo: Nobel, 242p, 2002.

GOLLOP, R.; FARHI, S.; PERL, A. Regulation of leucoanthocyanidin dioxigenase gene expression in Vitis vinifera. Plant Science, 161, p. 579-588, 2001.

HERTOG, M.G.L.; HOLLMAN, P.C.H.; van de PUTTE, B. Content of potentially anticarcinogenic flavonoids of tea infusions, wines and fruit juices. Journal of Agricultural Food Chemistry, v. 41, n. 8, p. 1.242-1.246, 1993.

INSTITUTO BRASILEIRO DE GEOGRAFIA E ESTATÍSTICA - IBGE. Sistema IBGE de recuperação automática. Censo agropecuário2006. Disponível em:< http://www.sidra.ibge.gov.br/bda/tabela/protabl asp? $\mathrm{z}=\mathrm{p} \& \mathrm{o}=20 \& \mathrm{i}=\mathrm{P}>$. Acesso em: 01 de julho de 2011.

IAL. Normas Analíticas do Instituto Adolfo Lutz. Métodos químicos e físicos para análise de alimentos. 3a ed. São Paulo, Instituto Adolfo Lutz, v.1, 2005.

KHAN, N.; MUKHTAR, H. Tea polyphenols for health promotion. Life Sciences, Oxford, v.81, n.7, p.519-533, 2007.

LEÃO, P. C. S.; SOARES, J. M. A Viticultura no Semi-Árido Brasileiro. EMBRAPA SemiÁrido, Petrolina, 2000.

MARTENS S., KNOTT J., SEITZ C: A., JANVARI L., YU S., FORKMANN G. Impact of biochemical pre-studies on specific metabolic engineering strategies of flavonoid biosynthesis in plant tissues. Bio. Eng. Journal, 14, 227-235, 2003.

MATOS, E. H. S. F. Processamento de Frutas Desidratadas. Dossiê Técnico. Centro de Apoio ao Desenvolvimento Tecnológico da 
Edithe Helena de Brito Santos et al.

Universidade de Brasília - CDT/UnB, 22 p., 2007.

MELLO, L.M.R.de. Atuação do Brasil no mercado vitivinícola mundial: Panorama 2007. Embrapa Uva e Vinho, 2007. Disponível em: $<$ http://cnpuv.embrapa.br/>acesso em: 16 de fev. 2011.

MONTEIRO, S. Frutas e derivados: da uva ao vinho. Ano 2. Edição 08. Dezembro de 2007. Disponivel em: $<$ http://www.ibraf.org.br/x files/revista08.pdf $>$ . Acesso em: 26 de fev. 2011.

MUÑOZ, A.M., CIVILlE,G.V., CARR,B.T. Sensory evaluation in quality control. New York: Van Nostrand Reinhold, 1992. 240 p.

NORTHOLD, M.D. et al. Patulin production by some fungal species in relation to water activity and temperature. Journal of Food Protection, Des Moines, v.41, n.11, p.885-890, 1978.

OLLAT, N., DIAKOU-VERDIN, P., CARDE, J. P., BARRIEU, F., GAUDILlERE, J. P. \& MOING, A. Grape berry development: A review. Journal International des Sciences de la Vigne et du Vin, 36, 109-131, 2002.

OLIVEIRA, M. E. C.; FERREIRA, A. F.; PODEROSO, J. C. M.; LESSA, A. C. V.; ARAÚJO, E. D.; CARNELOSSI, M. A. G.; RIBEIRO, G. T. Atividade de Água (Aw) em amostras de Pólen Apícola Desidratado e Mel do Estado de Sergipe. Revista da Fapese, v.4, n. 2, p. 27-36, jul./dez. 2008.

PUUPPONEN-PIMIÄ，R.; NOHYNEK， L.; MEIER, C.; KÄHKÖNEN, M.; HEINONEN, M.; HOPIA, A.; OKSMAN-CALDENTEY, K.-M. Antimicrobial properties of phenolic compounds from berries. Journal of Applied Microbiology, v. 90, p. 494-507, 2001.

RANKINE, Bryce. Manual Prático de Enologia. Zaragoza - Espanha: Editorial Acribia, 1989.

RETO, M.; FIGUEIRA, M. E.; FILIPE, H. M.; ALMEIDA, C. M. M. Teor de fluoretos em infusões de chá verde (camellia sinensis). Unidade Farmacologia e Farmacotoxicologia, Faculdade de Farmácia, Universidade de Lisboa. Quim. Nova, Vol. 31, No. 2, 317-320, 2008.

RIBÉREAU-GAYON, P. Interpretation chimique de la couleur des vins rouges. Vitis, 12:119-142, 1973.

ROGGERO, J. P.; COEN, S.; RAGONNET, B. Hight performance liquid chromatography survey on changes in pigment content in ripening grapes of Syrah. An Approch to anthocyanin metabolism. American Journal of Enology and Viticulture, 37 (1), 77-83, 1986.

SANTOS, E. H.B.S.; AZEVEDO, L. C.; BATISTA, P.R.B.; LIMA, M.S.; AZOUBEL, P.M. Secagem e caracterização fisicoquimica da uva isabel (vitis labrusca). CONNEPI, 2010.

SERVIÇO BRASILEIRO DE RESPOSTAS TÉCNICAS. 2005. Disponivel em: $<$ http://sbrt.ibict. upload/sbrt900-3.html $>$. Acesso em: 10 de julho de 2011.

SEYMOUR, G. B.; TAYLOR, J. E.; TUCKEY, G. A. Biochemistry of fruit ripening. London: Chapman \&Hall, 1993. $454 \mathrm{p}$.

\section{SHAHIDI, F. Natural Antioxidants: An Overview "in" Natural Antioxidants} Chemistry, Health Effects, and Applications. AOCS Press: Champaign, Illinois, p. 1-11. 1996.

SILVA, P. C. G.; CORREIA, R. C. Caracterização social e econômica da videira. In: SOUZA LEÃO, P. C.; SOARES, J. M. (Eds.). A viticultura no semi-árido brasileiro. Petrolina: Embrapa Semi-Árido, p. 19-32, 2000.

SOARES, M.; WELTER, L.; KUSKOSKI, E. M.; GONZAGA, L.; FETT, R. Compostos fenólicos e atividade antioxidante da casca de uvas Niágara e Isabel. Rev. Bras. Frutic. vol.30 no.1 Jaboticabal Mar.2008. 
Edithe Helena de Brito Santos et al.

SOUSA, J.S.I. Viticultura brasileira: principais variedades e suas características. Piracicaba: Fealq, 368p, 2002.

SOUZA-LEÃO, P. C.; PEREIRA, F. M. Avaliação de seis variedades de uvas sem sementes no submédio São Francisco. Pesquisa Agropecuária Brasileira, Brasília, v. 36, n. 4, p. 607-613, 2001.

SOUZA, A. M. de; MOURA, A. F. C. de.; BRITTO, W. S. F. a carga tributária sobre os insumos agrícolas utilizados na cultura da uva no Vale do São Francisco. - Petrolina, PE, 2008. 